
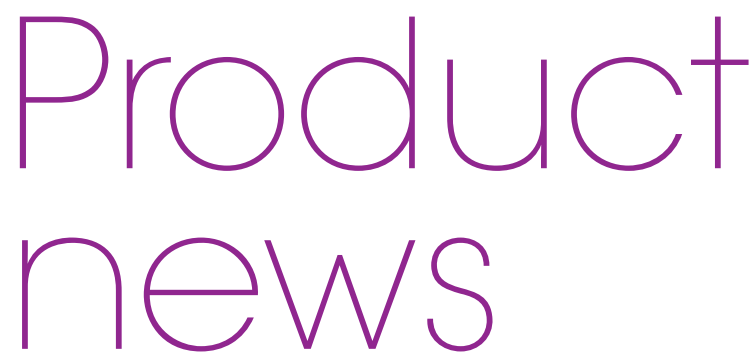

Product news is provided as a service to readers using text and images from

the manufacturer, supplier or distributor and does not imply endorsement

by BDJ Team. Normal and prudent research should be exercised before

purchase or use of any product mentioned.

\section{A NEW SOLUTION TO DRY MOUTH}

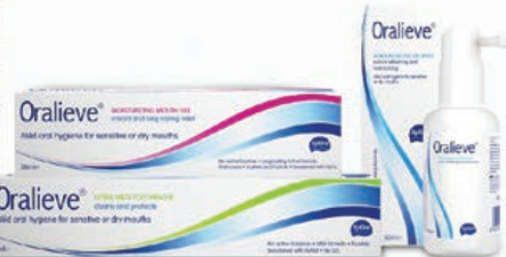

The Oralieve Dry Mouth Relief product range has been formulated with a unique combination of bioactive ingredients and enzymes to provide effective, long-lasting relief from dry mouth.

Oralieve Moisturizing Mouth Gel is a saliva substitute with intensive moisturisers to soothe and lubricate for long lasting relief. Ideal for use at night, Oralieve Moisturising Mouth Gel can be applied as often as required. Oralieve Moisturising Mouth Spray is ideal for use during the day providing onthe-go relief from dry mouth, and freshness.
Oralieve Ultra Mild Toothpaste contains no SLS and its mild flavours and ingredients are gentle on the mouth. An alcohol-free fluoride mouth rinse is also available.

Patients who are at risk of developing dry mouth include those with diabetes, on multiple medications, with Sjögren's syndrome or who have suffered from head and neck cancer. ${ }^{1,2}$ The impacts can make chewing, swallowing and talking difficult as well as leading to oral health complications such as caries and gingivitis.

www.oralieve.co.uk

\section{National Institute of Dental and} Craniofacial Research. Dry mouth (xerostomia). Available at https:// www.nidcr.nih.gov/oralhealth/topics/ drymouth/ (accessed 20 December 2016).

2. Dirix P, Nuyts S, Van den Bogaert W. Radiation-induced xerostomia in patients with head and neck cancer. Cancer 2006; 107: 2525-2534.
WHAT RED

MEANS IN WASTE MANAGEMENT

When considering 'red' in the best practice waste management colour coding system, here's what you need to know:

- 'Red' is the colour used to code anatomical waste

- Red waste can be hazardous or nonhazardous and includes any waste generated from the body

- Examples for this waste stream include body parts (excluding extracted teeth), blood bags, blood preserves and animal parts.

For obvious reasons, few dental practices will generate any 'red' waste, but it remains important to know what it means in order to complete the colour code.

Once waste containers (coded any colour) are full, they should be sealed and stored in a private location. It is necessary to work with a licenced contractor you can trust, such as Initial Medical, who will safely and legally collect the waste and dispose of it in the correct manner.

All Initial Medical technicians have undergone the required $\mathrm{ADR}$ training and they strive to always provide outstanding customer service.

Don't forget, if you or any member of your team has a question about safe and effective waste segregation and disposal, the experts at Initial Medical would be more than happy to help. For further information visit www.initial.co.uk/medical.

\title{
NEW APP LOOKS AT DIET AND THE TEETH
}

FoodForTeeth is a prevention based app designed by young dentists Prateek Biyani and Jasneet Gulati. The app officially launched on the iOS platform in November 2016 and has already been prescribed to patients in primary care.

The aim of FoodForTeeth is to educate patients about the causes of dental disease and how our diet is so crucial for our oral health. This is achieved by promoting the use of digital diet diaries as a dietary investigation, as well as through a traffic-light system database of common foods and drinks with their risk of caries and erosion.

The app is designed to be used very closely with the patient's dentist/DCP, so that the patient can present their diet diary via the FoodForTeeth app and engage in conversation about their diet. This can then allow tailored, specific dietary advice to be given as part of the preventative regime for the patient.

The app has been checked and edited by expert nutritionists and the dietary advice has been designed to be holistic, as much of the dietary factors that lead to caries are also linked to diabetes and obesity.

The designers of the app hope that $B D J$ readers will use FoodForTeeth as a diet investigation tool with their patients, and would welcome feedback to help improve the free app. Visit http://www.foodforteeth.com to find out more and to leave feedback.

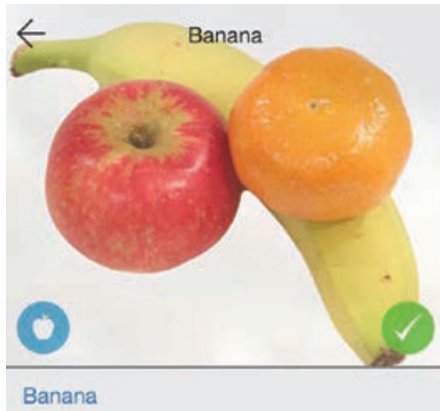

Fruits have intrinsic sugars which are less likely to cause decay than the refined extrinsic sugars. In terms of tooth decay, fruits are a low risk, healthy alternative to sugary snacks however fruits with citric acid particularly oranges and other citrus fruits are high risk of causing acid erosion of your teeth. Enjoy in moderation and follow our top tips to in 